\title{
Avranches - 16 rue Boudrie
}

$\mathrm{n}^{\circ} 3480$

\section{Denis Thiron}

\section{(2) OpenEdition \\ Journals}

Édition électronique

URL : http://journals.openedition.org/adlfi/16687

ISSN : 2114-0502

Éditeur

Ministère de la culture

Référence électronique

Denis Thiron, "Avranches - 16 rue Boudrie », ADLFI. Archéologie de la France - Informations [En ligne], Basse-Normandie, mis en ligne le 26 février 2016, consulté le 01 mai 2019. URL : http:// journals.openedition.org/adlfi/16687

Ce document a été généré automatiquement le 1 mai 2019.

(c) Ministère de la Culture et de la Communication, CNRS 


\title{
Avranches - 16 rue Boudrie
}

\author{
$\mathrm{n}^{\circ} 3480$
}

\section{Denis Thiron}

Lien Atlas (MCC) :

http://atlas.patrimoines.culture.fr/atlas/trunk/index.php?

ap_theme=DOM_2.01.02\&ap_bbox=-1.377;48.675;-1.336;48.702

1 Préalablement à la construction d'un immeuble d'habitation par la société SICCA au 16 de la rue Boudrie à Avranches, un diagnostic archéologique a été prescrit en raison de sa localisation dans le centre antique et médiéval de la ville.

2 Malgré un contexte archéologique a priori favorable, les résultats de cette opération sont assez limités. Seuls ont été mis en évidence des lambeaux d'occupation, probablement médiévale, dans la partie nord-ouest de l'emprise ainsi qu'une zone de fosses et de remblais successifs sur une épaisseur de 2,3 à 2,5 $\mathrm{m}$ partout ailleurs. Ce remblaiement fait suite à l'exploitation du site en carrière de sable et date vraisemblablement de la fin du Moyen Âge ou de l'époque moderne.

\section{INDEX}

Index géographique : Basse-Normandie, Manche (50), Avranches

Index chronologique : Moyen Âge, Temps Modernes

operation Diagnostic (EV) 


\section{AUTEURS}

\section{DENIS THIRON}

Inrap 